\title{
Decision-Making Power and Family Planning Use: A Case of Married Women in Kishapu District, Tanzania
}

\author{
Harrieth G. Mtae, PhD \\ ORCID: https://orcid.org/0000-0002-6059-378X \\ Department of Community Economic Development \\ The Open University of Tanzania \\ Corresponding Mail: mtaeharrieth14@yahoo.com
}

\begin{abstract}
Copyright resides with the author(s) in terms of the Creative Commons Attribution CC BY-NC 4.0. The users may copy, distribute, transmit and adapt the work, but must recognize the author(s) and the East African Journal of Education and Social Sciences
\end{abstract}

\begin{abstract}
This study analyzed the role of married women aged 15 to 49 years on their decision-making on various issues using a cross-section study design. It involved 130 respondents from Kishapu District, selected using multistage sampling. Data was collected using interviews and focus group discussions. Quantitative data was analyzed through frequencies and percentages while qualitative data was analyzed thematically. It is concluded that, spouses make decisions on the money earned by respondents $(60.2 \%)$. Decision on the money earned by respondent's spouses is made jointly $(48.1 \%)$ while $39.5 \%$ is made by their spouses as the sole decision-makers. Decision regarding respondents' health is made by respondents themselves $(46.5 \%)$ while $39.5 \%$ reported their spouses to decide for them. Regarding spouse's health care, joint decision-making was reported by $62.3 \%$ of respondents and $30.4 \%$ reported their spouses to decide on their own health care. Decision on respondent's use of contraceptives is conducted jointly by $69.1 \%$ while $19 \%$ is done by respondents alone. Decision on spouse's contraceptive use is made mostly jointly (80\%). Major household purchase is a joint decision issue by $51.7 \%$ but $44.4 \%$ reported spouses as sole decision-makers. Concerning visits to relatives and family, spouses are the decision-makers $(52.7 \%)$ while joint decision making is done by $42.6 \%$. The study recommends strategic interventions in family planning programs to encourage more visible involvement of women in household decision making including promoting couples' discussions on reproductive health and family planning in particular. Further, Policy makers in family planning and reproductive health care should put more efforts and focus on interventions and programs which target imbalance of power practices between couples in the household.
\end{abstract}

Keywords: Decision-making power; spouse; contraceptive use; health care; household purchase

How to cite: Mtae, H. G. Decision-Making Power and Family Planning Use: A Case of Married Women in Kishapu District, Tanzania. East African Journal of Education and Social Sciences 2(4), 136-145. Doi: https://doi.org/10.46606/eajess2021v02i04.0138.

\section{Introduction}

Household decision-making is a very important aspect in the use of family planning services. Women's decisions on family planning use have multiple benefits to the family and community at large and therefore cannot be ignored. Family planning services have been made widely available in most areas (United Nations Populations Fund,
2010). Despite these efforts, there are still constraints within households to realize the 'unmet need' especially in low-income countries' rural areas (United Nations Department of Economic and Social Affairs, 2015, Adamou, Iskarpatyoti, Agala and Meija, 2017). According to United Nations Department of Economic and Social Affairs (2015), worldwide $64 \%$ of married or in-union women in reproductive age use some form of contraception. 
The ability for these women to make decisions on various issues in the household including contraceptive use allows them to reduce unintended pregnancies, have the desired number of children and reduces the incidences of unsafe abortions.

Despite this realization, family environment in Africa is still the place where the domination relationship between the sexes occurs, the aim of which remains the subordination of gender (Alkema et al., 2016). However, in many societies, especially in developing or low-income countries, the status of women often limits their autonomy and ability to make decisions about many aspects of their own lives. Many such societies still have strong social structures that rigidly define the roles of men and women, usually encoded in religious, tribal and social traditions (Osamor and Grady, 2016; Dadi, Bogale, Minda \& Megersa, 2020). Osuafor, Maputle, and Ayiga (2018) emphasize that women's participation in decisionmaking on contraceptive usage remains crucial in the control of their reproductive life amidst the cultural relevance and socio-economic values. Reproductive health rights emphasize women's individual decisions on when to have children and how many they want but fall short in accounting for the realities in decision-making on contraception, especially in marital relationships where cultural and socio-economic factors play critical roles. In such societies, men might disapprove the use of contraceptives and refuse to give their consent. On the other hand, women might (incorrectly or not) believe that their husband disapproves contraceptives and decide not to approach him to get his consent in order to avoid conflict in case he is against it. Several studies have shown that there is little communication around family planning and contraceptive use for most couples (e.g. Shattuck et al., 2011, Hartmann, Gilles, Shattuck, Kerner \& Guest, 2012). Little or no communication implies that women do not know whether their husband approves contraceptive use or not ( $D^{\prime}$ Exelle and Ringdal, 2019).

According to the Tanzania Demographic and Health Survey (TDHS, 2016), the national modern contraceptive prevalence rate was $38 \%$ among married women of which $32 \%$ were using modern methods. It was further revealed that $61 \%$ of married women aged 15-49 wanted to avoid pregnancy, but of these women, $22 \%$ were not using family planning putting them at risk for unintended pregnancies. Among the unmarried sexually active women, the percentage of women who wanted to avoid pregnancy increased to $79 \%$ and "unmet need" reached $25 \%$ while for Shinyanga is $21 \%$ which is below the national level (TDHS, 2016). In spite of the strong social structures that rigidly define the roles of men and women in many of the households' undertakings, there is still limited studies that documented on the role of women's decision-making power on family planning use. Therefore, this study sought to investigate on Decision-Making Power and Family Planning Use: A Case of Married Women in Kishapu District, Tanzania.

\section{Study Area}

Kishapu District was officially inaugurated in July 2006 under the Local Government Act No. 7 of the year 1984 which establishes District Councils. Other districts in Shinyanga region include Kahama District Council, Kahama Town Council, Shinyanga District Council, and Shinyanga Town Council. The population of Kishapu District is 272,990, of which 137,721 are females and 135,269 are males with average household size of 6.3 people and an average population growth rate of 2.9 percent which is higher than the national average of 2.7 percent, according to the 2012 population census. The District is administratively divided into three divisions: Kishapu, Mondo and Negezi and these in turn are subdivided into 29 wards and 117 registered villages. Wasukuma, Wanyiramba and Wataturu are the major ethnic tribes in the area (URT, 2013).

Agriculture and livestock keeping are the two major economic activities of the people in the district employing 77.2 percent of the total labour force. The main food crops are sorghum, sweet potatoes, cassava, legumes, maize and paddy while the main cash crops are cotton, paddy and chickpeas. Livestock keeping includes cattle, goats, sheep, donkeys and poultry. Forestry, fishing and related activities are the second largest economic activity employing 7.3 percent, followed by mining and quarrying (3.5 percent), trade and commerce (2.7 percent), public administration and education sectors (2.3 percent) and others (6.8 percent). Kishapu District residents get health services from 2 hospitals, 4 health centers and 53 dispensaries. By 2021, there were 116 nursery schools, 122 primary schools, 28 secondary schools and 143 adult education centers (URT, 2013). 


\section{Research Methodology \\ Design}

This study employed a cross-sectional research design. The study population was married women aged between 15 and 49 years of age. The sampling unit was married women who live in a particular household in four villages of Uchunga, Kishapu, Mwakipoya and Mwamalasa. District Reproductive and Child Health Officers (DRCHO), religious leaders as well as elders were also interviewed for detailed information regarding decision-making on various issues and contraceptive use. Multi-stage sampling was used and it included both purposive sampling and simple random sampling procedures. Purposive sampling was used to capture qualified study areas and respondents and specifically it was used to select a representative district with low contraceptive use. One hundred and thirty married women were selected using simple random sampling. Quantitative data were collected using a semi-structured questionnaire and the interview was conducted in the participants' usual residence while the qualitative data were collected from key informants through focus group discussions. The questionnaire was first prepared in English and later contextualized to suit the research objective, local situations and language of respondents. The quality of the data was assured by translation to Swahili and retranslation to English, pre-testing of the questionnaire, training of the data collectors and close supervision of data collection processes. Descriptive statistics such as, frequency and percentages were computed to find distributions and magnitudes of individual variable among respondents and qualitative data were analysed using the thematic approach.

\section{Ethical consideration}

Approval to conduct research was sought in all stages of the study. Participants were informed on the purpose of the study and before interview, oral informed consent was sought. The women were further informed about the potential risk and benefits of participating in the study including the right to withdraw from the study whenever they want to. Furthermore, the assurance on the confidentiality of the information they provided was provided.

\section{Results and Discussions Socio-economic Characteristics \\ Age}

Age of respondents ranged between 15 and 49 years with the majority having the age of between 35 to 44 years $(34.9 \%)$ and 25 to 34 years $(33.4 \%)$ as indicated in Table 1 . The choice of age range between 15 and 49 years was done purposeful because individuals are still fertile and have a chance to bear children in the future if their fertility is not controlled. According to American Society for Reproductive Medicine (2012), the best reproductive years for a woman are in her twenties and thereafter fertility gradually declines, particularly after reaching thirty-five years. Normally the average age for menopause is 49 years, although some women in their mid-40s are incapable of conceiving.

Table 1: Respondents Characteristics

\begin{tabular}{lcc}
\hline Item & Frequency & Percent \\
\hline Age & & \\
$15-24$ & 28 & 21.7 \\
$25-34$ & 43 & 33.4 \\
$35-44$ & 45 & 34.9 \\
More than 44 & 13 & 10.1 \\
Education Level & & \\
Incomplete primary school & 21 & 16.4 \\
Complete primary school & 100 & 77.3 \\
Incomplete secondary school & 05 & 03.6 \\
Complete secondary school & 03 & 02.7 \\
Higher than secondary school & - & - \\
Type of Union & & 82.2 \\
Monogamous & 106 & 17.8 \\
Polygamous & 23 & \\
\hline
\end{tabular}

\section{Marital Status}

Marriage is the primary indication of the regular exposure of a couple to the risk of pregnancy and therefore it is important for fertility. Married women in the monogamous union were $82.2 \%$ and so the rest were in a polygamous marriage. 
Respondents who reported to be in monogamous marriage, some of them reported being married after a husband divorced his former wife. This kind of information is difficult to check whether the former wife is actually divorced or just separated and so this could affect the marital status results.

\section{Level of Education}

Respondents who reported to have completed primary school were $77.3 \%$ while those who did not complete primary school were $16.4 \%$ and only 2.7 percent had a secondary education but none of them had formal education beyond secondary school. This could be linked to the practice of early marriages which is common to the study area so that more cows in form of dowry could be brought to the family.

\section{Decision-making on the Use of Respondents Earned Money}

When asked who is responsible for deciding on how to use the money which they have earned, most respondents $(60.2 \%)$ reported that their spouses are the ones who make decisions on the use of the money they earn. About one third of respondents (33.3\%) reported making a joint decision with their spouses. Only 6.5\% reported being making their own decisions regarding the money they earn. Therefore, majority of respondents had low autonomy over the money they earned.

Table 2: Decision-maker on the Use of Respondent Earned Money

\begin{tabular}{llll}
\hline \multicolumn{1}{c}{ Characteristic } & \multicolumn{1}{c}{ Category } & Frequency & Percent \\
\hline Decision Making on the Use of Earned Money & Own Decision & 8 & 6.5 \\
by respondent & Spouse & 78 & 60.2 \\
& Joint decision & 43 & 33.3 \\
\hline
\end{tabular}

Table 3: Couples' Decision-making on the Use of Earned Money by the Spouse

\begin{tabular}{llll}
\hline \multicolumn{1}{c}{ Characteristic } & \multicolumn{1}{c}{ Category } & Frequency & Percent \\
\hline Decision making on the use of earned money & Respondent & 16 & 12.4 \\
by spouse & Spouse & 51 & 39.5 \\
& Joint decision & 62 & 48.1 \\
\hline
\end{tabular}

These findings differ from those obtained by TDHS (2016) which reported that more than half of married women $(55 \%)$ reported that decisions about how their cash earnings are used are usually made jointly with their husbands and more than one-third (36\%) said they make these decisions by themselves. Less than $10 \%$ of women reported that their husbands alone decide how their earnings are used. This could be associated with the fact that urban women are more likely to have autonomy on the use of the money they earn as compared to their counterparts in rural areas. According to Furuta and Swalay (2010) and United Nations Population Fund (2010), women's lower control over household resources results from limited participation in intrahousehold decision-making on spending. On the same note, women in low- and middle-income countries tend to have less bargaining power than their husbands, making them unable to do what they want. In a study conducted in Ethiopia, it was found that if women were given a cash transfer, only $33 \%$ would pick it up alone as opposed to $70 \%$ of men if the cash transfers were given to both of them (Benhassine, Devoto, F., Duflo, Dupas \& Pouliquen, 2015). During focus group discussions, it was established that women work very hard to earn money but they are obliged to inform their spouses on the earnings before they decide on how to use it. One woman remarked that:

"If you decide to keep it from him and accidentally, he finds out, even if it is 1,000 shillings, you will be bitten to the extent that you will not dare to repeat the same mistake. Men tend to take advantage of hardworking women, you may find a man having more than one woman and keep collecting money from them and sometimes use the same money with other women apart from the wife/wives " (a woman aged 37years).

\section{Decision-making on the Use of Earned Money by the Spouse}

In table 3, when asked about who decides on the use of money earned by their spouses, $48.1 \%$ of respondents reported joint decision on the money earned by their spouse while $39.5 \%$ reported their spouses as the sole decision-makers on the use of the money they earned. Only $12.4 \%$ reported being the main decision-makers on the earning of their spouses. These findings indicate that though joint decision making on the money earned by spouse exists in the study area, still a good number of respondents are accorded low decision-making power on cash earned by the spouse. 
These findings are supported by a report from TDHS (2016) that married women are somewhat less likely than their husbands to report that decisions about the husband's earnings are made jointly; $54 \%$ reported that these decisions are made together with the husband while $41 \%$ report that it is mainly the husband who makes decisions about how his earnings are spent. It was pointed out clearly during focus group discussions that, sometimes the husband may initiate the discussion on the use of the money he earned but still the final say is with the spouse as noted in the following comment by a respondent:

It is not a good habit for a man to make follow up on earnings of his wife if he is not going to allow his wife to have a say on his earnings. It is tempting us sometimes to think of using our money covertly, but when you think of the consequences once he finds out about it, you just let it go " (a woman aged 30 years).

It was also reported that a man may give his wife some money he has earned to keep for him, but the woman is not allowed to touch a penny and she has no power to question its use when the husband asked for it. One respondent was quoted saying:
You may find a man after harvesting and selling cotton, a husband may give his wife the responsibility of taking care of the money but, when the husband needs some money, he will have to ask from her wife. We women keep the money but we don't have much power over it. He can lie that he needs the money to buy a farm or another cow but he uses it for drinking alcohol and I can do nothing about it (a woman aged 47years).

\section{Decision-making on Health Care}

Women's decision-making autonomy is very vital and increases their ability to attend to their health and utilize health care facilities effectively. The joint decision regarding respondents' health was reported by $46.5 \%$ of respondents while $39.5 \%$ reported that their spouses are the ones who make decisions. Only $14 \%$ of respondents reported having autonomy regarding their health. A study by Islam (2018) in Bangladesh demonstrated that women who were in a position to make meaningful joint decisions with their husbands regarding their health care, their child health care, and visits to the family members or relatives were more likely to use family planning methods than those who decide by themselves about these matters.

Table 4: Decision-maker on Respondent's Health Care

\begin{tabular}{clcc}
\hline Characteristic & \multicolumn{1}{c}{ Category } & Frequency & Percent \\
\hline Decision-Making on Respondents' Health Care & Respondent & 18 & 14.0 \\
& Spouse & 51 & 39.5 \\
& Joint decision & 60 & 46.5 \\
\hline
\end{tabular}

These findings are supported by the TDHS (2016) report which indicated that $72 \%$ of respondents were engaged in decision making on their health care. However, these findings differ from those reported by Sougou,Bassoum, Faye and Leye (2020) in a study conducted in Senegal that only $6.3 \%$ of women had the freedom to make their own decisions about their health while $80.3 \%$ relied on their husbands or partners to make such decisions for them and only $13.4 \%$ made a joint decisions. The results of this study and from other African countries therefore indicate that women's autonomy over decision-making for their health is still weak. According to Butler, Walker, Pablo and Bartels (2021), for women to be able to control their reproduction, they must first achieve social status and dignity to manage their health, sexuality and to exercise their basic rights in society.
Some women reported to be making decisions jointly with their spouses regarding their health care. However, in some cases, if the spouse is not showing concern, a woman may just decide for herself to go to the health center if she has money. For some, they have to hold on until their spouses decide to help them, as commented by one of the respondents:

In this area, our husbands are the ones who make most of the decisions in our households. When a woman is having complications in giving birth, her husband may decide to let her be sterilized so that he can save the costs of taking her to the hospital every now and then, and if he needs more children he can just marry another woman (a woman aged 50 years).

The emphasis came from another woman that, it is uncommon for men to be concerned about their 
wives' health until the situation gets worse. Some women do not have money or they may have money but unable to decide by themselves whether to go to the health center or not and therefore they have to wait for their husband to act:

Caring for each other is very important, but many men are not ready to spend money for their wife's health until when the situation gets worse. Women have to bear the brunt for the sake of their children knowing if they decide to leave then the children are going to suffer. (Kishapu, woman aged 38years).

\section{Decision-maker on Spouse Health Care}

It was also important to establish respondents' views regarding their spouse's health care. In table 5 , joint decision-making was reported by the majority (62.3\%) of respondents, followed by $30.4 \%$ who reported their spouses to be taking care of their health by themselves. Small portion (7.3\%) of respondents reported to be able to decide for their husbands. These findings differ from those reported by TDHS (2016) that $66 \%$ of men made decisions about their health care and $30 \%$ made them jointly. Only in very rare instances, females were the decision makers on men's health.

Table 5: Decision-maker on Spouse Gealth Care

\begin{tabular}{clcc}
\hline Characteristic & \multicolumn{1}{c}{ Category } & Frequency & Percent \\
\hline Decision-maker on spouse Health Care & Respondent & 09 & 7.3 \\
& Spouse & 38 & 30.4 \\
& Joint decision & 78 & 62.3 \\
\hline
\end{tabular}

Table 6: Decision-making on Respondents' Contraceptive Use

\begin{tabular}{llcc}
\hline \multicolumn{1}{c}{ Characteristic } & \multicolumn{1}{c}{ Category } & Frequency & Percent \\
\hline Decision-Maker on Respondent Contraceptive & Respondent & 24 & 19.1 \\
Use & Spouse & 15 & 11.8 \\
& Joint decision & 87 & 69.1 \\
\hline
\end{tabular}

Table 7: Decision-making on Spouses' Contraceptive Use

\begin{tabular}{|c|c|c|c|c|c|}
\hline \multicolumn{3}{|c|}{ Characteristic } & \multirow{2}{*}{$\begin{array}{l}\text { Category } \\
\text { Respondent }\end{array}$} & \multirow{2}{*}{$\begin{array}{c}\text { Frequency } \\
13\end{array}$} & \multirow{2}{*}{$\begin{array}{c}\text { Percent } \\
10\end{array}$} \\
\hline Couples & Decision-Making & Spouses' & & & \\
\hline \multirow{2}{*}{\multicolumn{3}{|c|}{ Contraceptive use }} & Spouse & 13 & 10 \\
\hline & & & Joint decision & 104 & 80 \\
\hline
\end{tabular}

\section{Decision-making on Respondents' Family Planning Use}

Table 6 further revealed that $69.1 \%$ of respondents made joint decisions with their spouses on their use of contraceptives. Furthermore, 19\% reported to be making their own decisions on the use of contraceptives and $11 \%$ reported that their spouses are the ones to decide on their contraceptive use. It is very possible that the reported joint decision making could be attributed to the fear that the spouses would not agree on the use of contraceptives or being uneasy discussing such issues. Traditionally women are not expected to raise such issues thus leave the husband to make the final decision. For those who rely on their husbands to decide, it is not easy for them to plan for their family size as they do not have a say on contraceptive use.

The findings are in harmony with those by Yapo (2019) in Côte d'Ivoire which revealed that the decision-making power of husbands was stronger than that of women. Ideally, women feel empowered because family planning use gives them a sense of being capable of controlling their fertility and the use of female methods may result in increased perceived empowerment among women, resulting to the use of female methods covertly without discussing it with or involvement of their partners (Do and Kurimoto (2012).

\section{Decision-making on Spouses' Contraceptive Use}

In table 7, when respondents were asked to mention who makes decisions on spouses' use of contraceptives, joint decision-making was reported by $80 \%$ of respondents. Only 10 percent reported to be the sole decision maker and the other $10 \%$ reported spouse themselves.

A multi-country study conducted in Namibia reported that approval of the use of family planning by both spouses was significantly associated with women's use of any modern contraceptive method (Gebreselassie \& Mishra, 2007). Msovela et al. 
(2020) while working in Babati, Tanzania concluded that spouse joint decision making on family planning methods can be enhanced by providing couple counseling when accompanying their partners or when they visit health centers as clients. However, in the rural areas it is not customary for men to accompany their spouse to health clinics. Existing attitude, cultural and religious beliefs about sex, reproduction and women's right to protect them limits their ability to control and participate in decision-making with regards to the determination of fertility behavior Eguavoen, Odiagbe and Obetoh (2007). Like most other family decisions, fertility control is not always an individual affair as it may involves couple's cooperation in reaching the decision which depends also on the nature of the existing relationship between couples.

\section{Decision-making on Major Household Purchase}

Table 8 indicates that slightly above a half of respondents reported to have joint decision making on major household purchases (51.7\%), followed by $44.4 \%$ of respondents who reported that their husbands were the sole decision-makers on major purchases only 3.9 percent of women reported to be the sole decision-maker regarding the same.

Table 8: Decision Maker on Major Household Purchase

\begin{tabular}{clcc}
\hline Characteristic & \multicolumn{1}{c}{ Category } & Frequency & Percent \\
\hline Decision Maker on Major Household Purchase & Respondent & 5 & 3.9 \\
& Spouse & 58 & 44.4 \\
& Joint decision & 67 & 51.7 \\
\hline
\end{tabular}

Table 9: Decision-Maker on Respondents Visit to Family or Relatives

\begin{tabular}{llcc}
\hline \multicolumn{1}{c}{ Characteristic } & \multicolumn{1}{c}{ Category } & Frequency & Percent \\
\hline Decision-Making on Respondent Visit to Family & Respondent & 6 & 4.7 \\
or Relatives & Spouse & 69 & 52.7 \\
& Joint decision & 55 & 42.6 \\
\hline
\end{tabular}

Though most of the respondents reported joint decisions, these results showed that a large proportion of women had low entire decisionmaking power regarding major purchases in the household. These findings differ from those in URT (2010) which reported that the majority of men make decisions on major household purchases by themselves (57\%) or in consultation with their wives (36\%) while only $7 \%$ of women did so. However, they are also different from that of TDHS (2016) in which about $35 \%$ of respondents reported participating in deciding on major household purchases.

\section{Decision-making on Respondent Visit to Family and Relatives}

Table 9 indicates that $52.7 \%$ reported their spouse to be the decision-maker on whether respondents should visit their family and relatives or not while $42.6 \%$ reported joint decision making. Only $4.7 \%$ reported making their own decision on whether to visit family and relatives or not.

These findings connote that a good proportion of respondents have low decision-making power on whether they should visit their family and relatives or not. These findings differ from that reported by (TDHS, 2016) which found out that $58 \%$ of respondents reported participating in the decision- making on whether to visit family and friends or not. A study by Dadi, Bogale, Minda and Megersa (2020) in East, South Ethiopia found out that $51.7 \%$ of respondents reported joint decision making on the decision to visit family or relatives while $38.7 \%$ reported decision to be done by husbands alone. $A$ study conducted in Bangladesh by Uddin, Hossin and Pulok (2017) revealed that women consistently tended to underestimate the joint decision-making arrangement when compared to men. For example, while $61 \%$ of men reported that they jointly decide when visiting the wife's family or relatives, the corresponding figure for women readiness amounted to $52 \%$.

It was reported during focus group discussions that women are not allowed to go to visit their relatives or friends without permission from their husbands as reported by one of the respondents that:

Men are in control of women's movement as well. If a woman wants to visit her parents she will have to ask her husband and if the husband says no, then she will not go. However, in some cases, if she has a small child, a husband may instruct the child on a number of days to stay there, and if the wife will decide to overstay, the child will start to 
cry endlessly until the wife will decide to go back home.

Another respondent reported that men fear and mistrust when their wives go to visit family and relatives:

Normally men do not allow their wives to go and visit their parents or relatives for the fear of women cheating with other men, but also the fear that she will go and tell her relatives the way her husband is mistreating her (if he mistreats her) and that they will influence her to divorced (woman aged32years).

Index of Decision Making on Various Issues

An index was prepared to find out whether respondents have autonomy in decision-making about various issues in the household and whether there is any link to it with the use of family planning methods.

The results in Table 10 revealed that the majority of respondents had low autonomy (81.8\%). These findings could be a result of joint decision-making on various issues as reported by respondents in individual items in Table 2 to 9.

The results in Table 11 show that current contraceptive use and intention to use contraceptives was found to be highest (83.3\%) among respondents who had a high level of autonomy regarding decision making on various issues in the household. This is an indication that respondents' contraceptive use was associated with their level of autonomy.

Table 10: Respondents Level of Decision-making

\begin{tabular}{lcc}
\hline Level of decision making & Frequency & Percent \\
\hline High & 12 & 9.1 \\
Medium & 12 & 9.1 \\
Low & 106 & 81.8 \\
\hline
\end{tabular}

Table 11: Index of Decision- making on Various Issues and Contraceptive Use

\begin{tabular}{lcc}
\hline Level of decision making & \multicolumn{2}{c}{ Current contraceptive use } \\
& Frequency & Percent \\
\hline High & 09 & 83.3 \\
Medium & 04 & 33.3 \\
Low & 53 & 51.9 \\
N & 66 & 52.0 \\
& Intention to use contraceptives in the future \\
High & 09 & 83.3 \\
Medium & 07 & 66.7 \\
Low & 71 & 68.5 \\
N & 87 & 69.0 \\
\hline
\end{tabular}

According to Dadi, Bogale, Minda and Megersa (2020), women who participate in household decision-making are also able to participate in decisions related to family planning use since participation in household decision-making and decision-making power on family planning are more related. Therefore, high involvement in household decision making positively influences the use of modern contraception and future intention to use contraception.

\section{Conclusions and Recommendations Conclusions}

Spouses make decisions on the money earned by respondents by $60.2 \%$. Decision on the money earned by respondent's spouses is made jointly by $48.1 \%$ while $39.5 \%$ is made by their spouses as the sole decision-makers. Decision regarding respondents' health is made by respondents themselves by $46.5 \%$ while $39.5 \%$ reported their spouses to decide for them. Regarding spouse's health care, joint decision-making was reported by $62.3 \%$ of respondents and $30.4 \%$ reported their spouses to decide on their own health care. Decision on respondent's use of contraceptives is conducted jointly by $69.1 \%$ and $19 \%$ is done by respondents alone. Decision on spouse contraceptive use is made mostly jointly by $80 \%$. Major household purchase is a joint decision issue by $51.7 \%$ but $44.4 \%$ reported spouses as sole decision-makers. Concerning visits to relatives and family, spouses are the decisionmakers by $52.7 \%$ while joint decision making is done by $42.6 \%$. 


\section{Recommendations}

The study recommends strategic interventions in family planning programs to encourage more visible involvement of women in household decision making including promoting couples' discussions on reproductive health and family planning in particular. Further, Policy makers in family planning and reproductive health care should put more efforts and focus on interventions and programs which target imbalance of power practices between couples in the household. Including a notion of empowerment in school curricular is one of possible effective ways as it will be captured by both girls and boys at an early age

\section{References}

Adamou, B., Iskarpatyoti, B., Agala, C. and Meija, C. (2017), "Male engagement in family planning. Gaps in monitoring and evaluation", MEASURE Evaluation.

Alkema, L., Chou, D., Hogan, D., Zhang, S., Moller, AB, Gemmill A, Ma Fat, D., Temmerman, M., Mathers, C. and Say, L. (2016). Global, regional, and national levels and trends in maternal mortality between 1990 and 2015, with scenario-based projections to 2030: a systematic analysis by the UN maternal mortality estimation inter-agency group. Lancet.387(10017):462-74

American Society for Reproductive Medicine, (2012). Age and Fertility. A Guide for Patients, Revised 2012, Pg 3-4

Benhassine, N., Devoto, F., Duflo, E., Dupas, P. and Pouliquen, V. (2015), "Turning a shove into a nudge? A labelled cash transfer for education", American Economic Journal: Economic Policy 7(3): 86-125

Butler, M.G., Walker, M., Pablo, L.A. and Bartels, S. A. (2021). Relationship between women's decision-making power over their own health care and use of modern contraception in the Democratic Republic of the Congo: a cross-sectional secondary data analysis. BMC Women's Health 21, 309. https://doi.org/10.1186/s12905-021-01450$\mathrm{x}$

Dadi, D., Bogale, D., Minda, Z. and Megersa, S. (2020). Decision-Making Power of Married Women on Family Planning Use and Associated Factors in Dinsho Woreda, South
East Ethiopia. Open Access J Contracept (11),15-23 https://doi.org/10.214 7/OA JC.S2 25331

D'Exelle, B and Ringdal, C. (2019). Uptake of family planning services: An experiment on the husband's involvement, Unpublished.

Do, M. and Kurimoto, N. (2012). Womens empowerment and choice of contraceptive methods in selected Africans countries. International Perspectives Sexual Reproductive Health. 38(1),2333.doi:10.1363/3802312.PMID:22481146

Eguavoen, A.N.T., Odiagbe, S. O. Obetoh, G. I. (2007). The Status of Women, Sex Preference, Decision-Making and Fertility Control in Ekpoma Community of Nigeria. Journal of Social Science, 15(1):43-49

Furuta, M. and Salway, S. (2006) Women's Position within the Household as a Determinant of Maternal Health Care Use in Nepal. International Family Planning Perspectives, 32, 17- 27. https://doi.org/10.1 363/ 3201706

Gebreselassie, T. and Mishra, V. (2007). Spousal Agreement on Family Planning in SubSaharan Africa. DHS Analytical Studies No. 11. Calverton, MD: Macro International Inc.

Hartmann, M, Gilles, K., Shattuck, D., Kerner, B. and Guest, G. (2012), "Changes in couples' communication as a result of a maleinvolvement family planning intervention", Journal of Health Communication 17(7): 802-819.

Islam, A.Z. (2018). Factors affecting modern contraceptive use among fecund young women in Bangladesh: does couples' joint participation in household decision making matter?. Reprod Health 15, 112. https://doi.org/10.1186/s12978-018-0558-8

Msovela, J., Tengia-Kessy, A., Rumisha, S.F. et al. Male partner approval on the use of modern contraceptive methods: Factors determining usage among couples in Kibaha district, Tanzania. Contracept Reprod Med 5, $3 \quad$ (2020). https://doi.org/10.1 186/s408 34-020-00107-8

Osamor, P. and Grady, C. (2016). Women's autonomy in health care decision-making in developing countries: a synthesis of the 
literature. International Journal of Womens Health Vol. 8: 191-202.

Osuafor, G. N., Maputle, S. M., and Ayiga, N. (2018). Factors related to married or cohabiting women's decision to use modern contraceptive methods in Mahikeng, South Africa. African journal of primary health care \& family medicine, 10(1), e1-e7. https://doi.org/10.4102/phcfm.v10i1.1431

Shattuck, D., Kerner, B., Gilles, K., Hartmann, M., Ng'ombe, T. and Guest G. (2011), "Encouraging contraceptive uptake by motivating men to communicate about family planning: The Malawi male motivator project", American Journal of Public Health 101(6): 1089-1095.

Sougou, N.M., Bassoum, O., Faye, A. and Leye, M. M. (2020). Women's autonomy in health decision-making and its effect on access to family planning services in Senegal in 2017: a propensity score analysis. BMC Public Health 20, 872.https://doi.org/10.1186/s12 889 -020-09003-x

TDHS, (2016). Tanzania Demographic and Health Survey and Malaria Indicator Survey (TDHSMIS) 2015-16. Dar es Salaam/Tanzania: MoHCDGEC, MoH, NBS, OCGS, and ICF

Uddin, J., Hossin, M.Z. and Pulok, M.H. (2017). Couple's concordance and discordance in household decision-making and married women's use of modern contraceptives in Bangladesh. BMC Women's Health 17, 107. https://doi.org/10.1186/s12905-017-0462-3

United Nations Department of Economic and Social Affairs (2015), "Trends in contraceptive use worldwide 2015", United Nations Department of Economic and Social Affairs.

United Nations Population Fund (2010), “How universal is access to reproductive health? A review of the evidence", United Nations Population Fund.

URT (2010). Tanzania demographic and health survey. National bureau of statistics. Dar es salaam, Tanzania and ICF Macro Calverton Maryland, USA

URT (2013). 2012 population and housing census. National bureau of statistics, Ministry of finance, Dar es salaam and Office of chief government stastician, President's office, Finance, Economy and Development planning Zanzibar.

Yapo, Y.V. (2019). The Decision-making in Couples and Modern contraception use among Women in Côte d'Ivoire. Journal of Economics and Development Studies 7(2), 52-81 ISSN: 2334-2382 (Print), 2334-2390 (Online) 